\title{
Dynamic conformal cooling improves injection molding
}

\author{
Hybrid molds manufactured by laser powder bed fusion
}

\author{
Andreas Kirchheim $^{1} \cdot$ Yogeshkumar Katrodiya ${ }^{1} \cdot$ Livia Zumofen $^{1} \cdot$ Frank Ehrig $^{2} \cdot$ Curdin Wick $^{2}$
}

Received: 23 November 2020 / Accepted: 8 February 2021 / Published online: 8 March 2021

(C) The Author(s) 2021

\begin{abstract}
To achieve a certain visual quality or acceptable surface appearance in injection-molded components, a higher mold surface temperature is needed. In order to achieve this, injection molds can be dynamically tempered by integrating an active heating and cooling process inside the mold halves. This heating and cooling of the mold halves becomes more efficient when the temperature change occurs closer to the mold surface. Complex channels that carry cold or hot liquids can be manufactured close to the mold surface by using the layer by layer principle of additive manufacturing. Laser powder bed fusion (L-PBF), as an additive manufacturing process, has special advantages; in particular, so-called hybrid tools can be manufactured. For example, complex tool inserts with conformal cooling channels can be additively built on simple, machined baseplates. This paper outlines the thermal simulation carried out to optimize the injection molding process by use of dynamic conformal cooling. Based on the results of this simulation, a mold with conformal cooling channels was designed and additively manufactured in maraging steel (1.2709) and then experimentally tested.
\end{abstract}

Keywords Additive manufacturing · Laser powder bed fusion · Laser beam melting · Maraging steel · Hybrid-mold · Conformal cooling $\cdot$ Injection-molding

\section{Introduction}

The design of the mold temperature control system has a decisive influence on the cycle time and the molding accuracy of plastic components. As the geometric complexity of the component increases, the implementation of cooling channels in the mold becomes more and more difficult. In the past, tool inserts with close contour temperature control were usually produced by vacuum brazing. Today, additively manufactured mold inserts can be used to achieve complex channel guidance in all three

Andreas Kirchheim

andreas.kirchheim@zhaw.ch

Frank Ehrig

frank.ehrig@ost.ch

1 Centre for Product and Process Development, Zurich University of Applied Sciences, Winterthur, Switzerland

2 Institute of Material Sciences and Plastics Processing, Eastern Switzerland University of Applied Sciences, Rapperswil, Switzerland dimensions close to the mold's surface, thus ensuring homogeneous temperature distribution on the cavity surface and avoiding hotspots. Laser powder bed fusion(L-PBF) is the most widely used additive manufacturing process for the manufacturing of high-quality tools and other metal components [1,2].

\section{Background}

\subsection{Laser powder bed fusion}

Laser powder bed fusion (L-PBF), also known as selective laser melting (SLM), is a layer by layer process of manufacturing three-dimensional functional parts from a CAD model, where the energy of a laser beam is used to selectively melt the powder particles. In this research work, a Renishaw AM400HT selective laser melting system equipped with a 400-W SPI fiber laser was used. This was operated in pulsed mode with a spot size of $70 \mu \mathrm{m}$. In pulsed mode two additional parameters, the point distance $s_{p}$ and exposure time $t_{\mathrm{E}}$, are used to define the scan velocity $\mathrm{v}_{\mathrm{S}}(1)$. The point distance corresponds to the distance between each 
of the laser's exposure points, whereas the exposure time defines the duration of the laser exposure. The input volume energy density $E_{V}(2)$ is a function of the laser power $P_{L}$, scan velocity $\mathrm{v}_{\mathrm{s}}$, layer thickness $\mathrm{l}_{\mathrm{z}}$, and hatch spacing $\mathrm{h}_{\mathrm{s}}$ [3].

$v_{s}=\frac{s_{p}}{t_{E}}$

$E_{V}=\frac{P_{L}}{v_{s} \cdot h_{s} \cdot l_{z}}$

\subsection{Injection mold material 1.2709}

The maraging steel 1.2709 (also known as $18 \mathrm{Ni}-300$, 1.2709, X3NiCoMoTi 18-9-5) is one of the most used maraging steels in additive manufacturing. It presents excellent mechanical properties such as high strength and high toughness derived from the precipitation of intermetallic compounds rather than carbon content, and is therefore suitable for many injection molds and tools [4]. Due to its resistance to hardening effects, the welding properties of maraging steel 1.2709 are the most important features which make it easy to process with L-PBF. During the L-PBF process of maraging steel 1.2709, it remains in a ductile phase after rapid solidification and cooling from austenitizing temperatures, which prevents the likelihood of the material from cracking $[5,6]$.

The mechanical properties of maraging steel 1.2709 manufactured by L-PBF have higher yield and tensile strength compared to conventionally produced material. After ageing treatment, strength and hardness increase through the precipitation of iron-nickel intermetallic and there is an observed reduction in ductility [7, 8]. The microstructure of such specimens built additively consists of martensite with a small amount of austenite. However, the microstructure can be optimized by performing a solution treatment before ageing of additively built specimens, which can almost remove the austenite phase. Also, such built specimens have fine columnar and/or dendritic grains due to the rapid solidification of the melt pool. Therefore, solution and ageing treatments are recommended to change the grain orientation and grain growth of the martensite matrix [9].

In this paper, the L-PBF process parameters which were used for evaluating the mechanical properties of maraging steel 1.2709 are shown in Table 1.

Table 1 Process parameters of maraging steel 1.2709

\section{Parameter}

Laser power

$170 \mathrm{~W}$

Hatch spacing

$80 \mu \mathrm{m}$

Point distance

$55 \mu \mathrm{m}$

Exposure time

$90 \mu \mathrm{s}$
For tensile testing, 3 samples as-built and 3 samples which were heat-treated were used. For this heat treatment, a solution annealing at $850{ }^{\circ} \mathrm{C}$ for $1 \mathrm{~h}$ with air cooling and subsequent artificial ageing at $490{ }^{\circ} \mathrm{C}$ for $6 \mathrm{~h}$ with air cooling were carried out. All tensile specimens were machined according to DIN 50125 to create B5x25 tensile specimens and were tested according to EN ISO 68921. The mechanical properties which resulted are shown in Table 2. Here, it is clearly shown that the employment of the right solution and ageing heat treatment significantly increases tensile strength and at the same time decreases ductility, which is typical for this alloy [10]. Figure 1 shows a polished cross-section of test specimen with $0.20 \%$ porosity measured as a percentage of the face area.

\subsection{Conformal cooling}

The cycle time and quality of the injection molding process depends on the cooling system of the mold. One method of effective cooling is if cooling channels are designed as close as possible to the mold cavity.

The design of conventional cooling channels is limited by various manufacturing constraints, such as a drilling process, as shown in Fig. 2a, which leads to different proximity of the cooling channels to the mold cavity. This results in an uneven heat dissipation that leads to increased cycle time. On the other hand, using L-PBF technology makes it possible to create a conformal design of cooling channels at an equal distance to the mold cavity, as shown in Fig. 2b. This results in uniform heat dissipation. Thus, production efficiency in the injection molding process can be improved by implementing conformal cooling channels, which provides a significant improvement in cooling performance [12].

Furthermore, the design freedom of L-PBF can enable the manufacture of different cross-sections with varying profiles and surface finish. To date, many studies on the introduction of conformal cooling channels in injection molds have been carried out [13-16]. Successful design of conformal cooling channels can be achieved by considering the following criteria: a transient heat transfer condition, which dictates a maximum distance from the mold surface to cooling channel; pressure and temperature drop along the flow channel, and the strength of the mold [17].

To identify the quality of horizontal holes produced without a support structure in the L-PBF process of maraging steel 1.2709, a benchmark artefact was produced (Fig. 3). This artifact features holes with diameters 10 to $1 \mathrm{~mm}$ manufactured without a support structure to ascertain surface roughness in the overhang area. This also provides visible evidence that the overhang surface roughness increases the greater the diameter of the hole is. Thus, a hole of $10-\mathrm{mm}$ diameter has a high surface 
Table 2 Mechanical properties of maraging steel 1.2709 manufactured using L-PBF

\begin{tabular}{llllll}
\hline Source & HT condition & YS (MPa) & UTS (MPa) & A (\%) & E (GPa) \\
\hline Kempen et al. & As-built & $1214 \pm 99$ & $1290 \pm 114$ & $13.3 \pm 1.9$ & $163 \pm 4.5$ \\
$2011[7]$ & Heat treated (ageing $\left.480{ }^{\circ} \mathrm{C} / 5 \mathrm{~h}\right)$ & $1998 \pm 32$ & $2217 \pm 73$ & $1.6 \pm 0.26$ & $189 \pm 2.9$ \\
Tan et al. & As-built & $915 \pm 7$ & $1165 \pm 7$ & $12.44 \pm 0.1$ & - \\
$2016[8]$ & Heat treated (ageing $\left.490{ }^{\circ} \mathrm{C} / 6 \mathrm{~h}\right)$ & $1967 \pm 11$ & $2014 \pm 9$ & $3.28 \pm 0.05$ & - \\
Renishaw[11] & As-built & $1016 \pm 8$ & $1141 \pm 7$ & $7.3 \pm 1$ & $160 \pm 5$ \\
& Heat treated (ageing $500^{\circ} \mathrm{C} / 6 \mathrm{~h}$ ) & $1753 \pm 20$ & $1806 \pm 6$ & $5.5 \pm 1$ & $170 \pm 8$ \\
ZHAW & As-built & $839.3 \pm 13.7$ & $1074.0 \pm 19.6$ & $15.0 \pm 0.4$ & $169.3 \pm 5.8$ \\
& Heat treated (solution $\left.850^{\circ} \mathrm{C} / 1 \mathrm{~h}\right)$ & $1987.3 \pm 45.4$ & $2058.6 \pm 39.1$ & $5.6 \pm 0.6$ & $201.7 \pm 2.9$
\end{tabular}

$H T$, heat treatment; $Y S$, Young's modulus; UTS, ultimate tensile strength; $A$, elongation; $E$, elastic module

roughness in the overhang area due to a lack of heat dissipation.

\subsection{Dynamic conformal cooling of the mold insert}

The use of conformal cooling is particularly interesting for variothermal mold temperature control in injection molding. This dynamic mold temperature control method is used to achieve a certain optical quality (e.g., for foamed components or shiny surfaces) or an improved mold surface (e.g., microstructures). When injecting the molten material, the mold temperature on the cavity surface is increased. For energy use and economic reasons, it is reasonable to use only the cavity area variothermally. This temperature increase of the cavity surface during the injection phase can be achieved by channels fed with a supply of hot water, ceramic heating elements, and induction [18].

Standard cooling procedure is achieved by the circulation of water through the cooling channel. The advantage

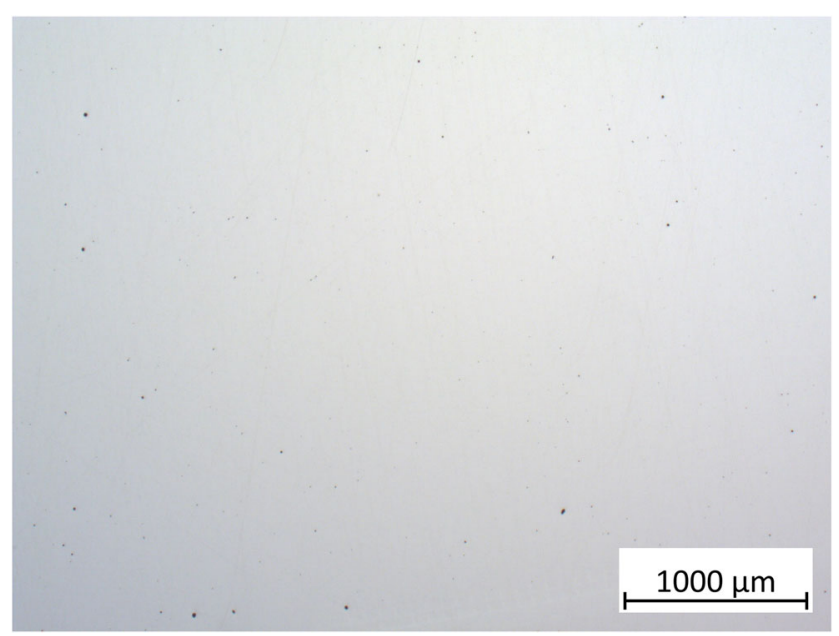

Fig. 1 Polished cross-section of test cube of L-PBF manufactured of maraging steel 1.2709 specimens of "water-water variothermal temperature control" is the freedom of design and the fact that both hot and cold water flows through the same channels. Figure 4 indicates

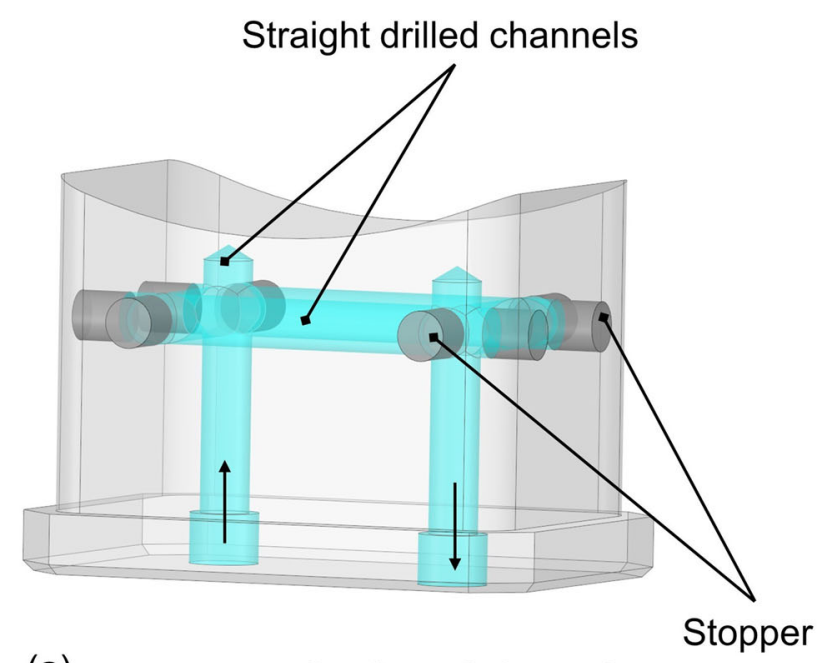

(a)

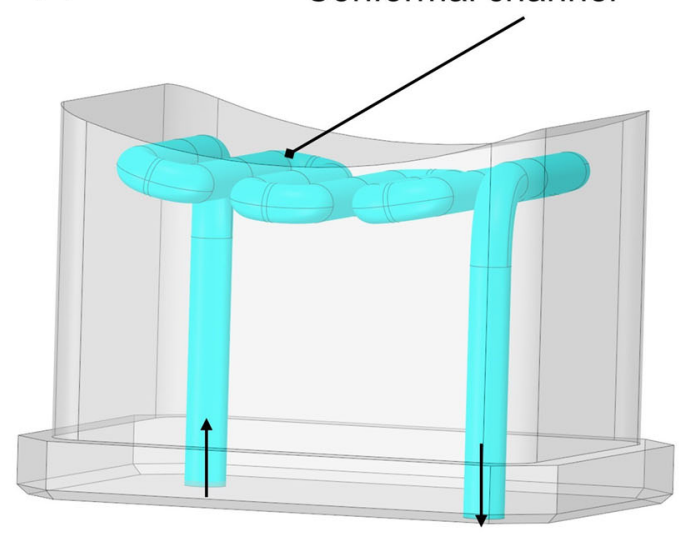

(b)

Fig. 2 Representation of a conventional cooling(top) and $\mathbf{b}$ conformal cooling(bottom) around the injection mold insert 


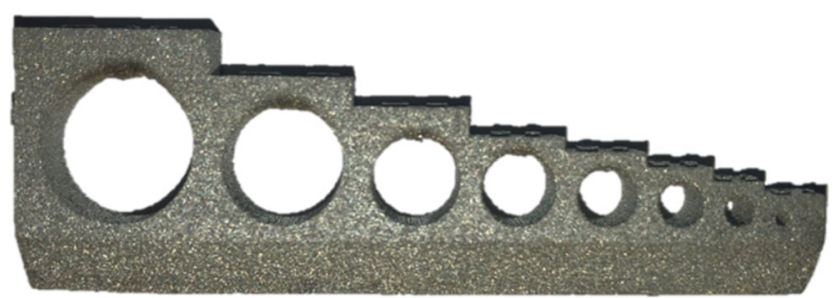

Fig. 3 Test artifact with different diameters of horizontal holes (from left: D10, D8, D6, D5, D4, D3, D2, D1 in mm)

the difference in temperature profile in the cavity with and without variothermal tempering. Switching between hot and cool water is done by a switching unit coupled to the injection molding machine. The heating and cooling of the mold halves are more efficient, the closer the cooling channels are to the cavity surface, since the thermal mass of the mold area that needs to be heated or cooled is thus reduced.

\section{Molds manufactured by L-PBF}

\subsection{Design of the mold inserts}

To demonstrate this concept, a witch's hat (see Fig. 5) designed as a bottle opener, including the related injection

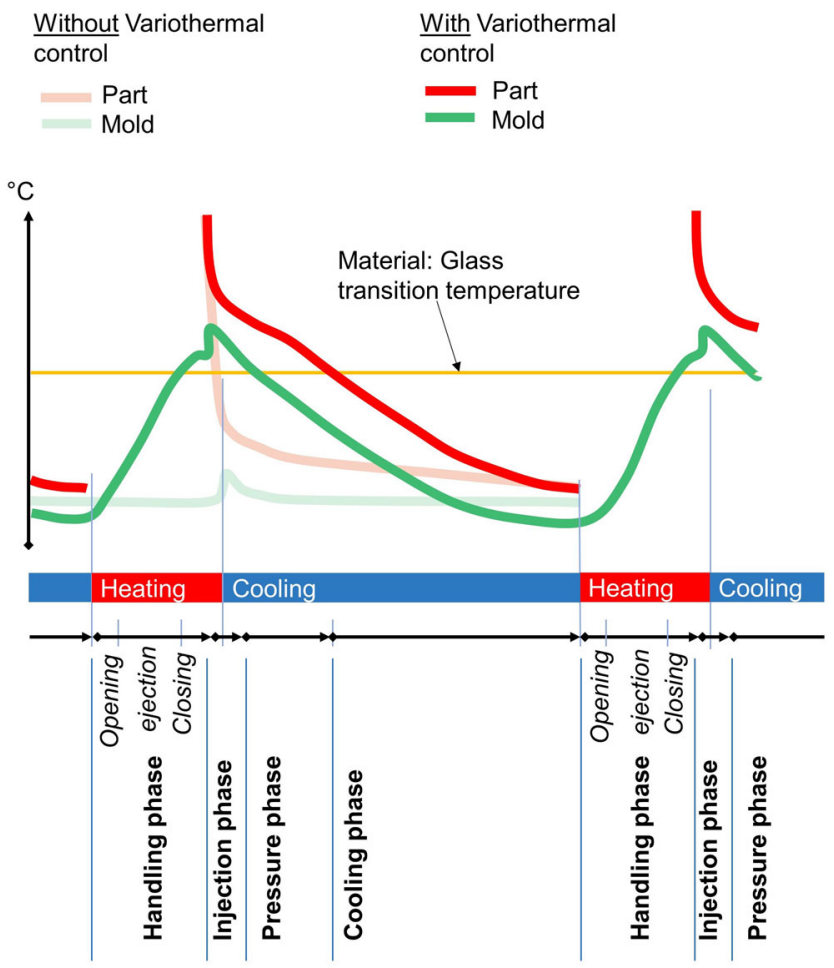

Fig. 4 Temperature profile in the cavity with and without variothermal tempering [19]

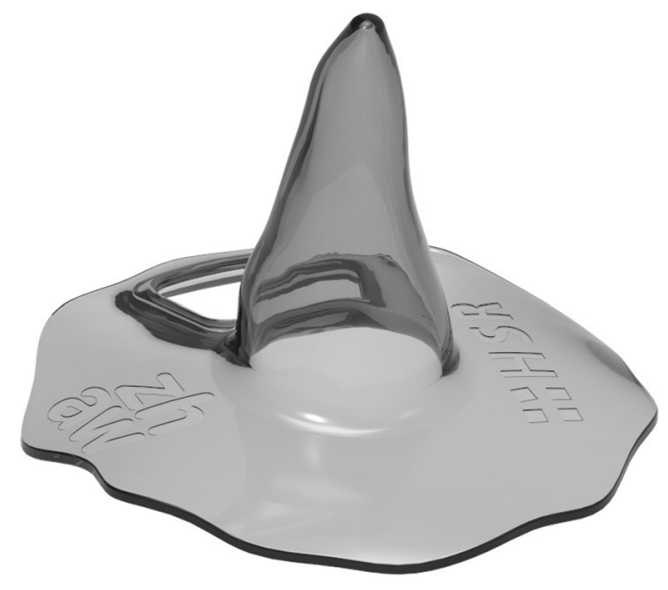

Fig. 5 Design of demonstrator; a witch's hat as a bottle opener

mold, was developed. In this case, homogeneous tempering would not be possible.

In order to minimize these disadvantages, a near-contour tempering in the two mold inserts was developed. The design of the inserts, the conformal cooling channel, and the thermal design were carried out in compliance with the design guidelines for additive manufacturing [20][21][22]. The design aims were to achieve homogeneous temperature distribution on the cavity surface on both mold inserts of the injector and the ejector side. The complete design of the injection mold is shown in Fig. 6.

On the injector side, the mold insert is manufactured entirely additively (Fig. 6a). In addition to the cooling channels close to the cavity, the mass of the mold insert for additive manufacturing (L-PBF) was brought down as much as possible in order to reduce the overall build time and cost. This reduction of mass also decreased thermal stress in the component. To reduce the mass, hollow spaces were added to areas of the mold inserts which were subjected to less stress (Fig. 7a). The mold insert on the ejector side (Fig. 6b) was designed as a hybrid tool. This means that the complex tool structure with the cooling channels close to the cavity was manufactured additively using L-PBF on a conventionally manufactured baseplate. In order to avoid excessive warping of the hybrid part, the baseplate was designed with a thickness of up to $50 \mathrm{~mm}$. This increases the structural stiffness compared to a standard build plate of 20 25 -mm thickness. Furthermore, the volume of the additive part was minimized. In particular, hollow spaces (Fig. 8) at the hybrid interface, the connection of the baseplate, and the additive part were integrated to reduce the energy input for the first layers of the L-PBF process.

\subsection{Thermal simulation of injection mold inserts}

To test the conformal design of the cooling channels, filling simulations were carried out with the plastic injection 
Fig. 6 Section view of complete injection mold (left) with injector and ejector sides and relative mold inserts $(\mathbf{a}, \mathbf{b})$
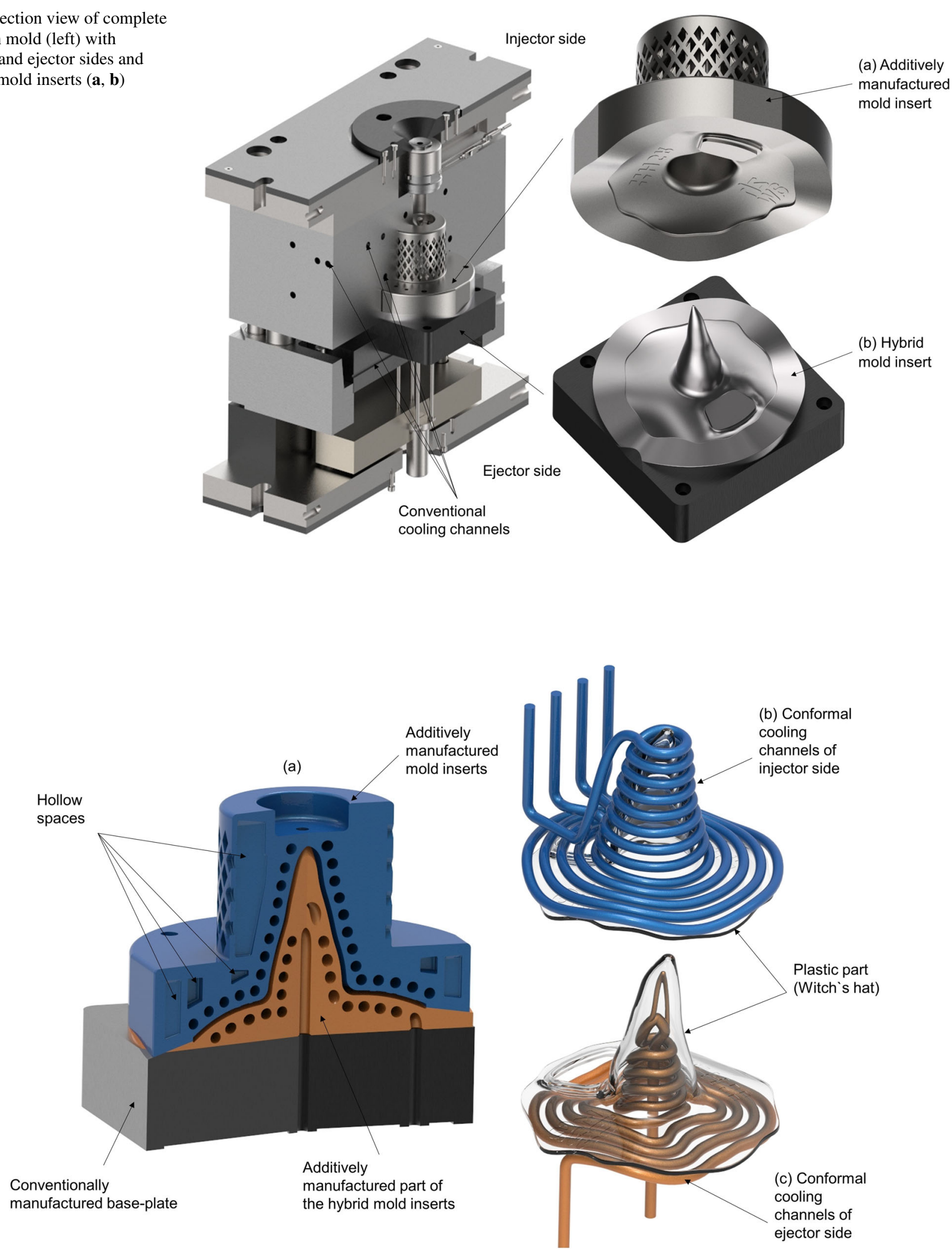

Fig. 7 a Section view of ejector side (orange) and injector side (blue) of mold with incorporated conformal cooling channels near to cavity; b conformal cooling channels of the injector side mold insert; c conformal cooling channels of the ejector side mold insert 


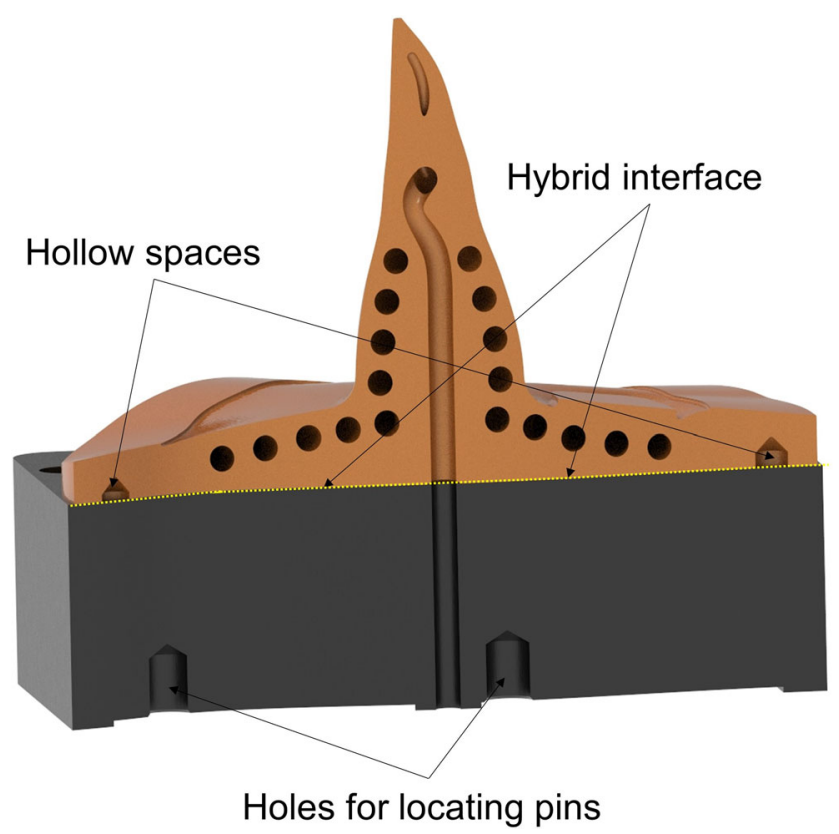

Fig. 8 Hollow spaces and holes for locating pins in hybrid mold insert

molding simulation software Moldex3D. In addition to the injection molding process itself, the temperature distribution in the mold can also be simulated. The result of the transient thermal cooling simulation of the ejector side of the mold is shown in Fig. 9. Here, the temperature distribution at the end of the holding pressure phase is displayed.

The heat distribution with conformal cooling is more homogeneous and at a lower level compared to that using conventional cooling channels. This means that the molded part is cooled more efficiently and lower cycle times can be achieved. Only the temperature in the area of the tip is higher. Due to the position of the injection point of the molded part, this is also where the greatest heat caused by the melting process occurs. The simulation was carried out with static tempering of the mold. It was assumed that the cooling channels contain water flowing at $80^{\circ} \mathrm{C}$ and 4 lit/min. The simulation predicted a loss of 3 bars in pressure with conformal cooling channels.

\subsection{Filling simulation of injection molding process}

Grilamid TR55 natural was the plastic material used. For the simulation, a melt temperature of $295^{\circ} \mathrm{C}$ was assumed. Figure 10 shows the temperature of the molded part at different intervals during the filling simulation. The cooling of the molded part is quite homogeneous; only the areas around the metal insert for the bottle opener cool down faster.

With conventional cooling, a cycle time of $17 \mathrm{~s}$ can be achieved, whereas with conformal cooling channels a reduction of $24 \%$ to $13 \mathrm{~s}$ is indicated. Times during which the mold is open or time required for inserting the metal insert with a handling system have been ignored here. The results are based on simulations, as there is no mold with conventional cooling for comparison.

\subsection{Manufacturing of the mold inserts}

As a first step, the mold insert on the injection side was manufactured using L-PBF. Then, the cavity was post-

Fig. 9 Heat distribution at the end of the holding pressure phase, ejector side of the mold (left, conformal cooling; right, conventional cooling)
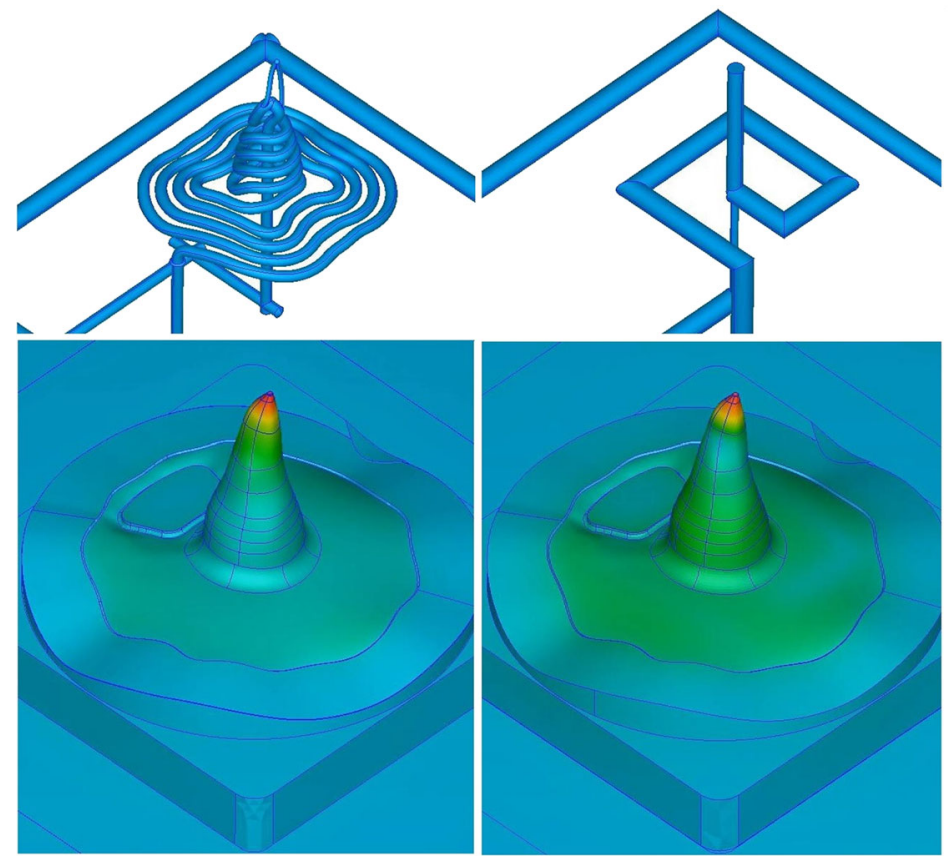
Fig. 10 Temperature during filling simulation of plastic part

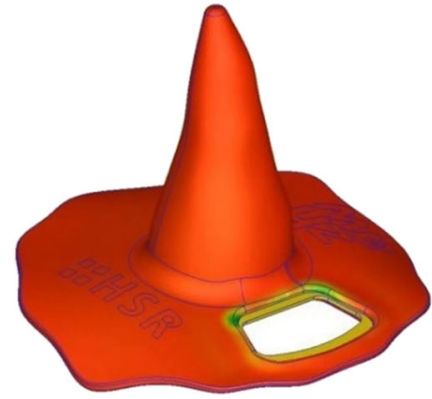

$1.175 \mathrm{~s}$ after Injection (End of filling)

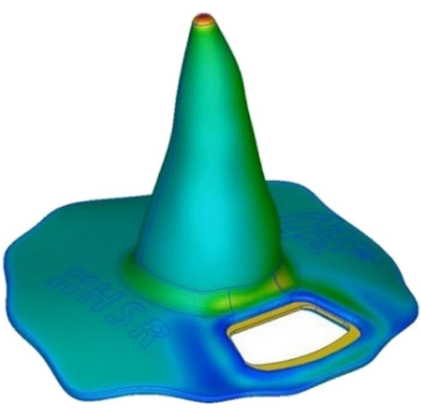

$8.366 \mathrm{~s}$ after Injection (During cooling)

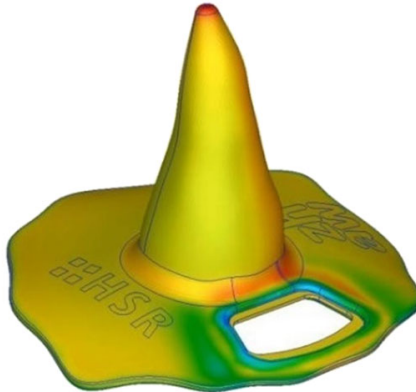

$3.498 \mathrm{~s}$ after Injection (During holding pressure)

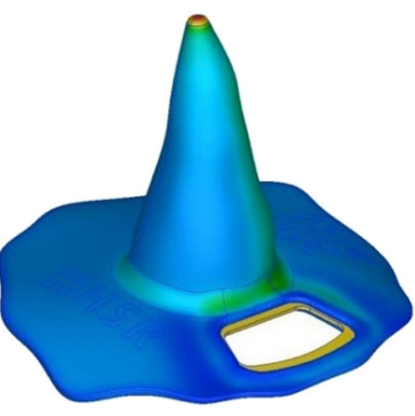

12.175 s after Injection (End of cooling)
Temp $\left[{ }^{\circ} \mathrm{C}\right]$

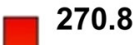

244.8

218.9

193.0

167.1

141.1

115.2

89.3

76.3 processed using die-sinking EDM to increase the accuracy and to reduce the surface roughness.

Figure 11 depicts the manufacturing of the mold insert on the ejector side, which is designed as a hybrid part. The baseplate was manufactured with conventional machining. The plate was mounted in the L-PBF system via a zeropoint clamping system (two defined locating pins on the underside of the baseplate as shown in Fig. 11). The LPBF process was carried out using a Renishaw AM400HT laser melting system. Subsequently, the hybrid mold insert was cleaned of metal powder and removed from the build chamber. The remaining powder material inside the cooling channels was extracted using pressurized air and a vacuum cleaner (wet separator). For final finishing, the hybrid mold insert was clamped in the machining center using a zeropoint clamping system. In this way, reclamping errors can be avoided.

\subsection{Experiment}

We examined the temperature distribution in the mold cavity and the heating or cooling rates. During the injection molding process, it is difficult to measure the temperature on the mold surfaces, as these are not accessible. Therefore, the mold halves are tempered in a non-installed state (dry test). The temperature distribution on the mold surface is recorded with a thermal imaging camera. Because of this, the mold surface needs to be coated with an anti-reflection spray.

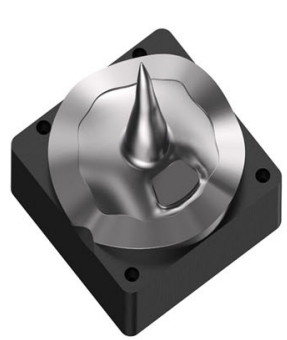

CAD-model Hybrid mold insert
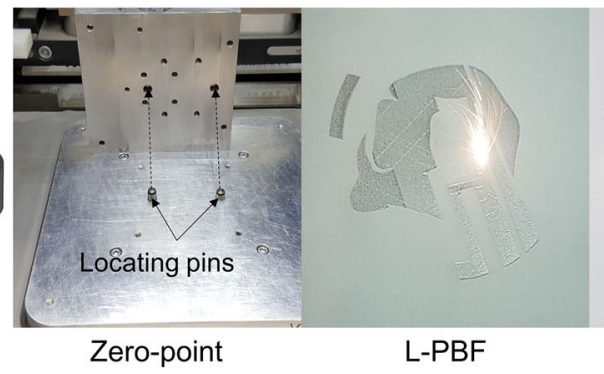

clamping system

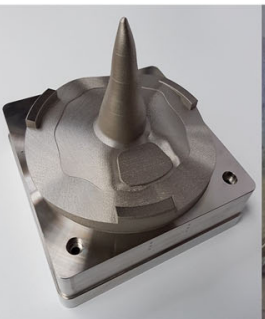

Hybrid mold insert after L-PBF process

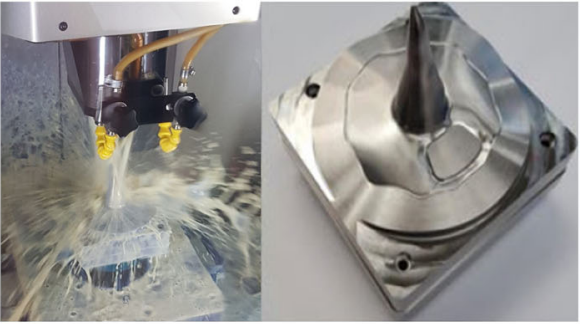

Machining post-processing

Finished hybrid mold insert

Fig. 11 Manufacturing steps of the hybrid mold insert of the ejector side 


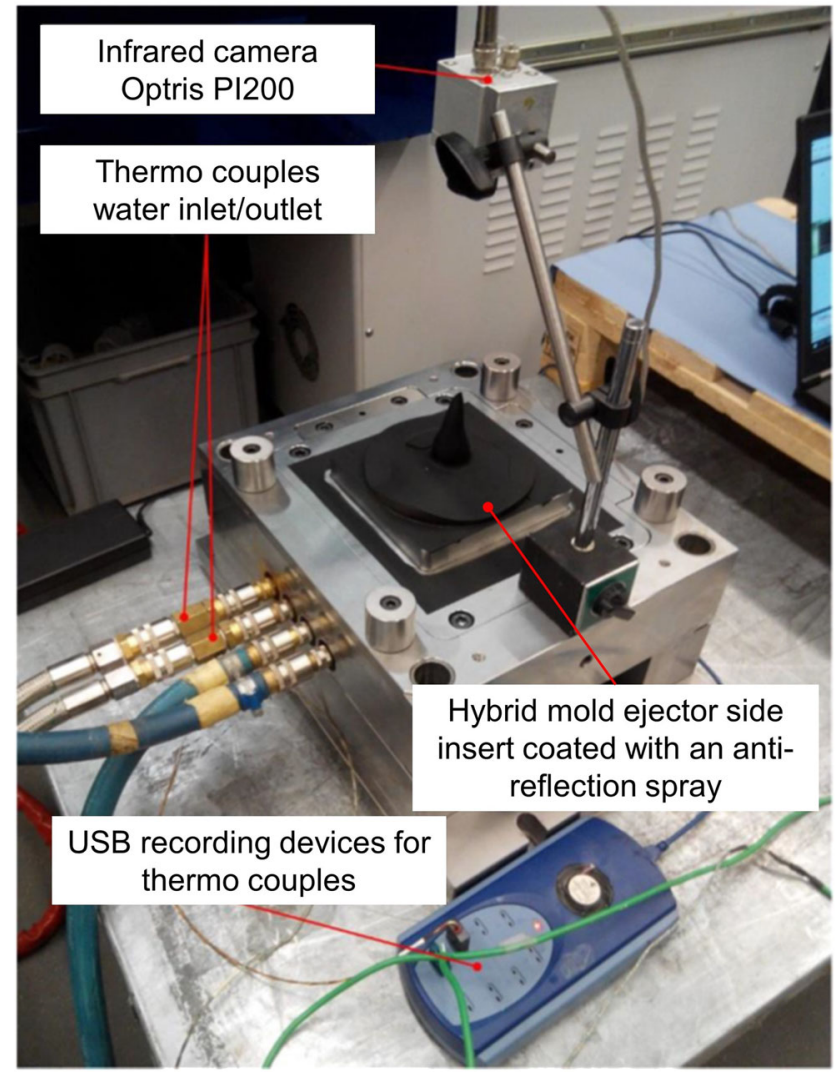

Fig. 12 Experimental setup

The water temperatures are measured with thermocouples at the inlet and outlet of the additive manufactured cooling circuits. Two temperature control units and a switch unit were used for the variothermal tempering of the mold. The experimental setup for the hybrid mold insert ejector

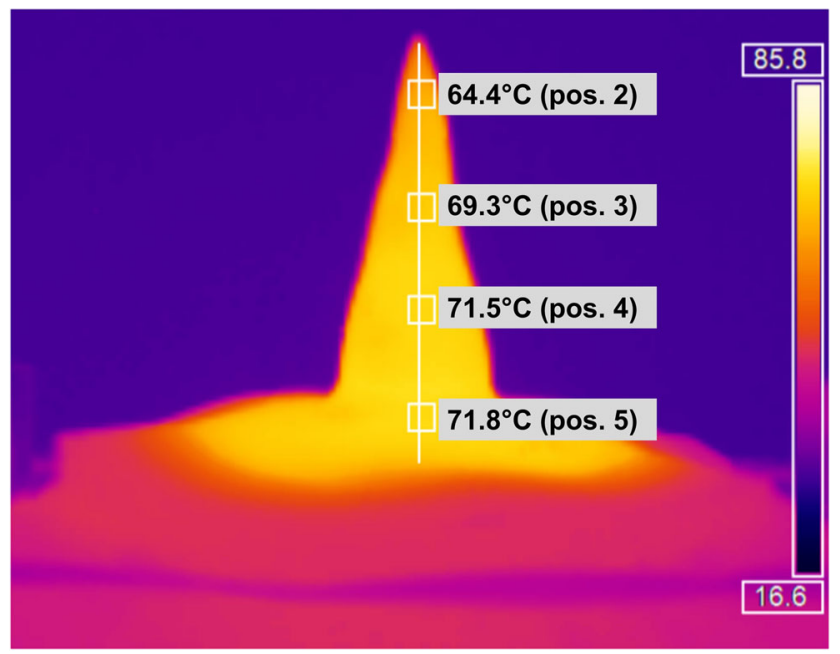

Fig. 13 Lateral view of the ejector hybrid mold insert showing the measuring positions and their respective temperatures (water inlet $=80$ $\left.{ }^{\circ} \mathrm{C}\right)$

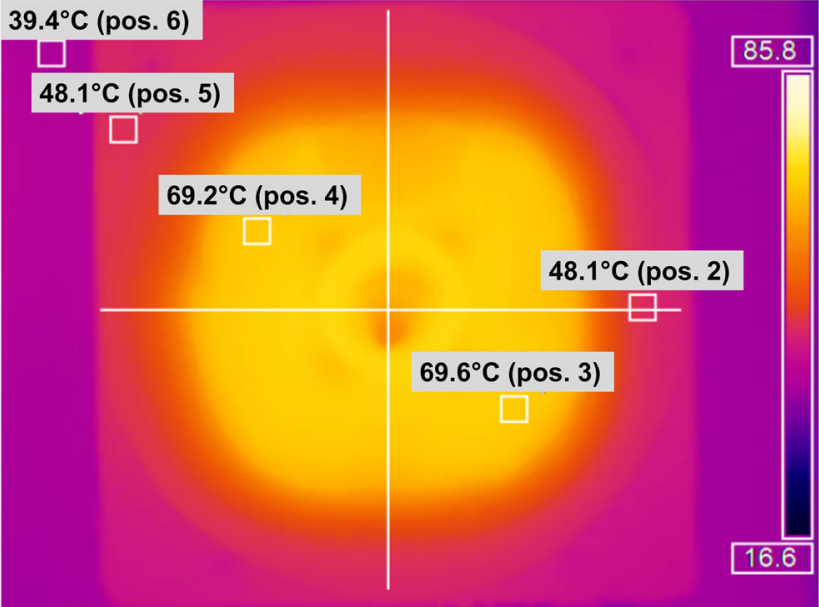

Fig. 14 Overhead view of the ejector hybrid mold insert showing the measuring positions and their respective temperatures (water inlet $=80$ $\left.{ }^{\circ} \mathrm{C}\right)$

side is shown in Fig. 12. The temperature of the water inlet is kept constant at $80^{\circ} \mathrm{C}$.

Figure 13 provides a lateral view showing the measuring positions and their respective temperatures and Fig. 14 a corresponding overhead view.

In Fig. 13, a decrease in the temperature from base to tip can be seen. Also, the temperature profile of the upper hat tip indicates inferior tempering of the tip compared to the brim. The temperature distribution is in general very homogeneous and the maximum temperature difference in the mold cavity is negligible.

Figure 14 shows an even heat distribution within the cavity. The temperatures of the baseplate (pos. 6) and the hybrid plate (pos. 5) remain unchanged during the heating phase, which is as intended. Also, the temperature of the edge point (pos. 2), which does not belong to the mold cavity, remains low.

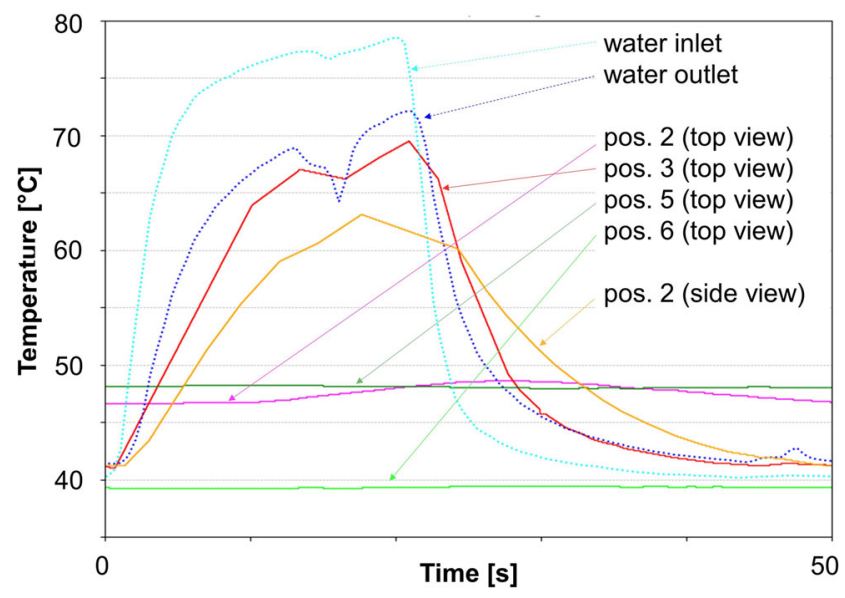

Fig. 15 Temperature profiles at measuring points with variothermal tempering $\left(40 / 80{ }^{\circ} \mathrm{C}\right)$ of the ejector mold insert 
Fig. 16 Mounted molds in injection molding machine for manufacturing of the demonstrator witch's hat (bottle opener) with high quality of reflective surfaces

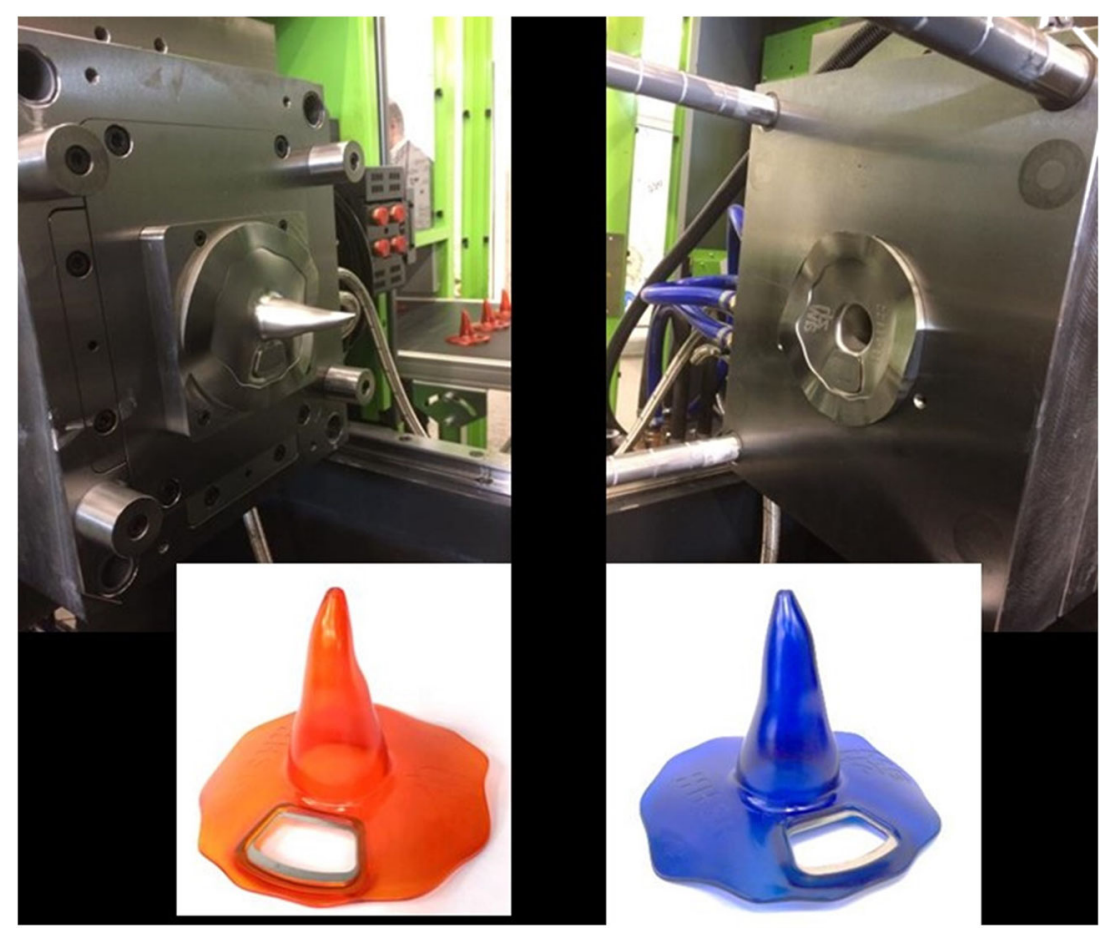

Figure 15 shows the heating and cooling behaviors of the cavity (ejector mold insert) at different measuring points with variothermal tempering.

Figure 16 shows the mounted molds (ejector side, left nozzle side, right) on the injection molding machine and the demonstration object (witch's hat bottle opener). Since the witch's hat functions as an experimental part, the accuracy does not play a decisive role. Much more important is the visual appearance of the part. The witch's hat has a beautiful surface with a high gloss, achieved by the variothermal mold tempering. These results are very satisfactory and the mold will be used for further trials. One possible investigation could be the verification of the overall cycle time through experimentation on the injection molding machine. The rationale being that the mold has only been employed in trial mode to date. During trial mode, it has been shown that the pressure loss in the cooling system is approximately 5 bar. The pressure drop in the experiment is 2 bar higher than that of the simulation. This is due to the high degree of surface roughness of the cooling channels in the additive manufactured mold. However, the surface roughness of the cooling channels could be improved by flow grinding, which would reduce this pressure loss.

\section{Conclusion}

In this work, the development and additive manufacturing process (L-PBF) of a complex hybrid injection mold with dynamic conformal cooling has been presented. It documents a reduction of the cycle time and an improvement in the surface quality of the injection molded part. The design of the conformal cooling was based on the simulation results, with the aim of achieving uniform and faster cooling in the mold insert. Before the additive manufacturing of the mold inserts, the LPBF process parameters were optimally set for maraging steel 1.2709. For the additive manufacturing of the hybrid mold insert on the ejector side, a thicker than customary base plate was used. It demonstrates that this reduces the warpage caused by the thermal stresses from the laser melting process. A simple zero-point clamping system was developed and employed to avoid re-clamping errors during the finishing process on a machining center. In addition, an experiment to measure the cooling and heating behaviors at the mold surface was conducted. Various other tests of the performance of the conformal cooling channels with dynamic mold temperature control were also carried out. These were compared with the thermal and rheological simulation results. Results showed a $24 \%$ reduction in cooling time and produced optimal surface quality of the molded parts.

Author contribution Andreas Kirchheim, Yogeshkumar Katrodiya, and Livia Zumofen contributed additive manufacturing of injection molding tool including material investigation, design of conformal cooling channel. Frank Ehrig and Curdin Wick contributed injection molding process including concept of dynamic cooling process and experiment test result. 
Funding Open Access funding provided by ZHAW Zürcher Hochschule für Angewandte Wissenschaften. The authors have no relevant financial or non-financial interests to disclose.

\section{Declarations}

Ethical approval The manuscript will not be submitted elsewhere until the editorial process is completed. The design and manufacturing process partially published in Kunststoffextra 1/2, 2019, swiss magazine. The new or extended work was carried out with material investigation of injection molding material 1.2709 and dynamic tempering process of conformal cooling including experiment setup, test and results.

Consent to publish The author transfers to Springer the non-exclusive publication rights.

Conflict of interest The authors declare no competing interests.

Open Access This article is licensed under a Creative Commons Attribution 4.0 International License, which permits use, sharing, adaptation, distribution and reproduction in any medium or format, as long as you give appropriate credit to the original author(s) and the source, provide a link to the Creative Commons licence, and indicate if changes were made. The images or other third party material in this article are included in the article's Creative Commons licence, unless indicated otherwise in a credit line to the material. If material is not included in the article's Creative Commons licence and your intended use is not permitted by statutory regulation or exceeds the permitted use, you will need to obtain permission directly from the copyright holder. To view a copy of this licence, visit http:// creativecommonshorg/licenses/by/4.0/.

\section{References}

1. Ampower GmbH \& Co. KG. (2020) Metal additive manufacturing market report 2020, Hamburg, Germany

2. Wohlers T (2018) C.T., Wohlers Report 2018: 3d printing and additive manufacturing state of the industry, Fort Collins, Colorado USA

3. Zumofen L, Kirchheim A, Dennig H-J (2020) Laser powder bed fusion of $30 \mathrm{CrNiMo} 8$ steel for quenching and tempering: examination of the processability and mechanical properties. Progress Addit Manuf 5(1):75-81

4. Casalino G, Campanelli SL, Contuzzi N, Ludovico AD (2015) Experimental investigation and statistical optimisation of the selective laser melting process of a maraging steel. Opt Laser Technol 65:151-158

5. Schober J (2019) Parametric analysis of 1.2709 maraging steel manufactured by LPBF EasyChair Preprint, vol 1061. Amberg, Germany

6. Mazur M, Leary M, McMillan M, Elambasseril J, Brandt M (2016) SLM additive manufacture of H13 tool steel with conformal cooling and structural lattices. Rapid Prototyp J 22(3):504-518
7. Kempen K, Yasa E, Thijs L, Kruth J-P, van Humbeeck J (2011) Microstructure and mechanical properties of selective laser melted 18Ni-300 steel. Phys Procedia 12:255-263

8. Tan C, Zhu K, Tong X, Huang Y, Li J, Ma W, Li F, Kuang $\mathrm{T}$ (2016) Microstructure and mechanical properties of $18 \mathrm{Ni}-$ 300 maraging steel fabricated by selective laser melting. In: Proceedings of the 2016 6th International conference on advanced design and manufacturing engineering. Atlantis Press, Paris

9. Mutua J, Nakata S, Onda T, Chen Z-C (2018) Optimization of selective laser melting parameters and influence of post heat treatment on microstructure and mechanical properties of maraging steel. Mater Des 139:486-497

10. VDI-Richtlinie (2013) Additive manufacturing processes, rapid manufacturing Beam melting of metallic parts - Qualification, quality assurance and post processing VDI 3405/Part, vol 2. BeuthVerlag GmbH, Berlin

11. Renishaw Material Datasheet (2017) Maraging steel M300 powder for additive manufacturing, UK

12. Mielonen M (2016) Improving production efficiency of injection molding process by utilization of laser melted tool inserts with conformal cooling, Master thesis, Aalto University - School Engineering, Espoo, Finland

13. Park H-S, Dang X-P (2017) Development of a smart plastic injection mold with conformal cooling channels. Procedia Manuf 10:48-59

14. Mercado-Colmenero JM, Martin-Doñate C, Rodriguez Santiago M, Moral-Pulido F, Rubio-Paramio MA (2019) A new conformal cooling lattice design procedure for injection molding applications based on expert algorithms. Int J Adv Manuf Technol 102:17191746

15. Evens T, Six W, De Keyzer J, Desplentere F, Van Bael A (2019) Experimental analysis of conformal cooling in SLM produced injection moulds: effects on process and product quality. AIP Conf Proc 2055:70017

16. David H, Luka Č, Janez K (2017) Cooling simulation of conformal cooling injection mould insert produced by hybrid manufacturing. Tehnički vjesnik 24(4):981-986

17. Xu X, Sachs E, Allen S (2001) The design of conformal cooling channels in injection molding tooling. Polym Eng Sci 41(7):12651279

18. Bürkle E, Burr A, Müller A, Kübler M (2017) Injection molding: high-speed mold heating. In: Kunstsoffe international, vol 10, pp 144-148

19. HB-Therm AG (2017) Switching unit for Variothermal Control, Product catalogue 2017-10, St. Gallen, Switzerland

20. VDI-Richtlinie (2015) Additive manufacturing processes, rapid manufacturing: design rules for part production using laser sintering and laser beam melting VDI 3405/Part, vol 3. Beuth Verlag GmbH, Berlin

21. Klahn C, Meboldt M, Fontana F (2018) Entwicklung und konstruktion für die additive fertigung: grundlagen und methoden für den einsatz in industriellen endkundenprodukten. Vogel Business Media, Würzburg

22. Adam GAO, Zimmer D (2014) Design for additive manufacturing: element transitions and aggregated structures. CIRP J Manuf Sci Technol 7(1):20-28

Publisher's note Springer Nature remains neutral with regard to jurisdictional claims in published maps and institutional affiliations. 